Editorial

\title{
"Great Expectations": Reflections on Possible Analogies between our Patients and the Characters of Charles Dickens
}

\author{
Giuseppe Milano ${ }^{1}$ \\ ${ }^{1}$ Department of Orthopaedics, Catholic University, Service of \\ Shoulder Surgery, Agostino Gemelli University Hospital, Rome, Italy \\ Joints 2017;5:131-132.
}

In this issue of Joints, we publish an interesting article by Lawrence and colleagues entitled "Expectations of Shoulder Surgery are not Altered by Surgeon Counseling of the Patient." 1

The authors of this article conducted a valid analysis of a population of patients who had consented to undergo shoulder surgery. Using a dedicated interview tool (Shoulder Surgery Expectations Survey by the Hospital for Special Surgery), they measured the expectations of these patients regarding the proposed treatment. This was done both before and after appropriate and standardized preoperative counseling, which was provided at patients' first visit, when they consented to the treatment. The data analysis showed that information provided to the patients by the physician produced no significant variation in the expectations of patients regarding the treatment, and these expectations were not significantly correlated with sociodemographic factors or variables related to the type of surgery. As the authors themselves suggest, this study prompts us to reflect upon two questions that assume considerable strategic value in modern medicine, given that these are increasingly based on the needs of the patients and careful evaluation of the real "value" of the treatment they may receive: ${ }^{2}$ What influences a patient's expectations regarding a treatment and to what extent, are these expectations shaped or modified by physician counseling? Although it has been shown that the subjective improvement produced by a treatment is often proportional to the patient's expectations, ${ }^{3}$ it is also true that allowing the patient to develop expectations that are disproportionate to the estimated and expected effect of a treatment may increase the risk of an unsatisfactory, and even disappointing, subjective outcome.

The expectations formed by orthopaedic patients depend on several variables (age, gender, type of activity, type of surgery, etc.), many of which have been analyzed with conflicting results, possibly because of confounding factors. ${ }^{4-8}$ Among these variables, patient information appears to play a key role and therefore impacts the potential patient satisfaction at follow-up. However, the literature is not unanimous on this point either, ${ }^{5,9}$ and this leads researchers, like Lawrence and colleagues, ${ }^{1}$ to question the adequacy and effectiveness of our current physician-patient communication strategies. Specialist counseling will furnish patients with a considerable amount of information that they may end up forgetting or even fail to take in, but at the same time, doctors are not using potentially more effective means of communication to their best advantage. One of these, not to be underestimated, is communication through social media. Internet is, indeed, full of medical information allowing patients to find out about their condition and treatment and prepare for their medical consultation, but online medical information tends to be exchanged between lay users and on social media platforms.

Moreover, it is known that health care providers are reluctant to engage in online interactions with patients through these channels, and indeed are often tacitly or openly opposed to this type of communication. ${ }^{10}$

A further consideration is that published research on this topic consists of observational studies that analyze a situation at a given time and, may be for this reason, report conflicting results. Indeed, expectations, by definition, concern the perception of an event or condition that has not yet come about and can therefore only be imagined; as such, these change over time as a result of events, new information, and encounters that may precede or follow the medical consultation. Although this consultation is a meeting that can certainly modify the patient's expectations, we cannot say how long this takes to occur; it is likely that each individual processes information at a different rate and in a different way, which depends on his/her perceptions of his/her condition, the cultural tools he/she is able to draw upon to interpret information, his/her coping strategies, and all the other factors that have played a part in generating his/her expectations up to that point. Sometimes, "great expectations," as we see in the homonymous novel by Charles
Address for correspondence Giuseppe Milano, MD, Department of Orthopaedics, Service of Shoulder Surgery, Agostino Gemelli University Hospital, Largo Agostino Gemelli, 00136, Rome, Italy (e-mail: giuseppe. milano@unicatt.it).
DOI https://doi.org/

10.1055/s-0037-1607230. ISSN 2282-4324.
Copyright @ 2017 Georg Thieme Verlag KG Stuttgart · New York
License terms

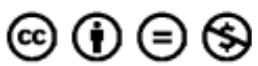


Dickens, ${ }^{11}$ are nothing other than an aspiration to be "different." As we see with Pip, the novel's protagonist, these are illusions that can result in dashed hopes. Furthermore, the great expectations referred to in the title of the novel are not only Pip's, but also those of all the characters he meets along his way, which end up influencing and changing his own. Eventually, Pip, to find his true expectations, has to move away. But first he has to be disappointed; he has to shed his great, but false, expectations in order to reconcile himself with the real ones.

\section{References}

1 Lawrence C, Maltenfort M, Lazarus M, Abboud J, Williams G, Namdari S. Expectations of Shoulder Surgery are not Altered by Surgeon Counseling of the Patient. Joints 2017;5(03):133-137

2 Milano G. Joint preservation of knee: what is its value? Joints 2017;5(02):57-58

3 Jain D, Nguyen LL, Bendich I, et al. Higher patient expectations predict higher patient-reported outcomes, but not satisfaction, in total knee arthroplasty patients: a prospective multicenter study. J Arthroplasty 2017;32(9S):S166-S170
4 Henn RF III, Ghomrawi H, Rutledge JR, Mazumdar M, Mancuso CA, Marx RG. Preoperative patient expectations of total shoulder arthroplasty. J Bone Joint Surg Am 2011;93(22):2110-2115

5 Koenen P, Bäthis H, Schneider MM, Fröhlich M, Bouillon B, Shafizadeh S. How do we face patients' expectations in joint arthroplasty? Arch Orthop Trauma Surg 2014;134(07):925-931

6 Plath JE, Saier T, Feucht MJ, et al. Patients' expectations of shoulder instability repair. Knee Surg Sports Traumatol Arthrosc 2017. Doi: 10.1007/s00167-017-4489-7

7 Skatteboe S, Røe C, Fagerland MW, Granan LP. Expectations of pain and functioning in patients with musculoskeletal disorders: a cross-sectional study. BMC Musculoskelet Disord 2017;18(01):48

8 Jaworski M, Rzadkiewicz M, Adamus M, et al. Primary care patients' expectations regarding medical appointments and their experiences during a visit: does age matter? Patient Prefer Adherence 2017;11:1221-1233

9 Cole BJ, Cotter EJ, Wang KC, Davey A. Patient understanding, expectations, and satisfaction regarding rotator cuff injuries and surgical management. Arthroscopy 2017;33(08):1603-1606

10 Benetoli A, Chen TF, Aslani P. How patients' use of social media impacts their interactions with healthcare professionals. Patient Educ Couns 2017. Doi: 10.1016/j.pec.2017.08.015

11 Dickens C. Great Expectations. Chapman and Hall, London, UK,1861 